latter by its illustrious associations and strong traditions in the earth sciences. Both centres were woll placed, moreover, for field oxcursions in the southern and northern parts of Great Britain.

At the congress attontion was focused particularly on modern work involving experiments on the hydraulies of sodimentary processes, which should lead eventually to a fuller knowledge of the silting of harbours and estuaries, among other things. The congress was also concernod with the application of sophisticated statistical techniques to the production of simulation models, for example, and to the more accurate prediction of oil, gas and metal-bearing deposits. There was discussion of the geotechnical properties of clays, which have important economic applications in civil ongineoring. In addition, biological and chomical aspects of sedimentation received full attention, while the more traditional fields of research were not neglected.

There were two major innovations in the organization of the congress which may be of interest to other scientists. First, the proceedings will not be published. Privately, many cynical remarks aro expressed about the somewhat gratuitous proliferation of the litorature by "symposium volumos", much of which consists of papers summarizing work already published or which is shortly to appear in print in the established scientific journals. Nevertheless, there is widespread resignation at the collusion of publishers and scientists anxious to promote their subject, which the organizers of the Sedimentological Congress have endeavoured to rosist. An added advantage is that contributors to public discussions should feel less inhibited if they know that their remarks are not being recorded for posterity. Howovor, to permit as much time as possible for free discussion, contributors had their short papers cyclostyled as preprints for membors of the congress, so that their verbal presentation was restricted to a few minutes. These preprints also served the function of "travel vouchers" for those delegates unfortunate cnough not to be ablo to acquire their expenses in other ways.

Secondly, an attempt was mado to counteract the frustration that arises at so many conferences when the chairman, operating to a strict time schedule, is obliged to terminate a discussion just when it is becoming lively. Each day of the congress was therefore so organized that, following general lectures by distinguished scientists and formal discussion groups in the various specialized research fields, at which short papers were read and commented on, delegates had the opportunity to convene informal discussion groups at the end of the afternoon session, to pursue furthor topics that had provoked a widespread interest. There seemed to be general consent that these informal sessions tended to be among the most stimulating of the whole congress.

\section{New Looks at Disulphide Bonds}

\section{from our Correspondent in Molecular Biology}

Disulphide bonds are known to play an important part in maintaining the conformation of those proteins - the great majority--in which they occur. When the disulphide bonds of a protein are in the reduced (broken) state, they must be reoxidized before the native conformation can be regained. It is also generally true that in the native protein they display a considerable, though variable, resistance to cleavage.

Thus in a survey of a large number of proteins, Davidson and Hird (Biochem. J,, 104, 473; 1967) find that the majority cannot be appreciably reduced by glutathione and a few others react to a small extent. When the native structure is weakened or disrupted by heat or limited proteolysis, the disulphide bonds become available for reaction. Now in ribonuclease, which has four disulphide bonds, Davidson and Hird (ibid., 480) find that reduction begins at a temperature of $50^{\circ} \mathrm{C}$, but it is observed that the enzyme then becomes a mixture of the fully intact and completely reduced forms. Thus it appears that the reduction of the first disulphide bond is rate-limiting, in that it makes the remainder instantly accessible by (presumably) provoking a conformational collapse. It has not been possible to establish that it is one in particular of the four cystines which acts as a hingepoint for the conformation.

A remarkable case in which differential reactivity of different disulphide bonds is strikingly apparent is reported by Seon (J. Biochem., Tokyo, 61, 606; 1967). This concerns the Japanese enzyme (as one may call it), Taka-amylase 4 . 'This molecule has four disulphide bonds and a cysteine residue, which is unavailable to reagents in the native state. When incubated with sodium borohydride as the reducing agent at $80^{\circ} \mathrm{C}$, the appearance of titratable sulphydryl groups with time occurs in a stepwise manner. Although there is some variation between different preparations, the best results show three perfectly developed plateaux. 'The first corresponds to two titratable groups, deriving from reduction of a single labile disulphide bond; one further group is titrated at the second plateau, and is identified by labelling and peptic digestion experiments as the single hidden cystcine residue of the native protein, which thus becomes available after scission of the first disulphide bond. One implication is that the conformational relaxation is slow compared with the disulphide reduction. The reaction then continues, with at least one further plateau. One of the most curious aspects of this remarkable reaction is the substantial conservation of enzyme activity up to the second plateau. Thus, although a conformational change must occur to liberate the hidden cysteine residue, the enzymatically important parts of the conformation are preserved (or reform in the presence of substrate).

Also in a current article (Pontremoli et al., Proc. US Nat. Acad. Sci., 58, 286; 1967), a case is described in which the formation of an extraneous disulphide bond by an enzyme may act as a metabolic control mechanism. The cnzyme, fructose diphosphatase, is activated by some, though by no means all, disulphide reagents, notably by eystamine which occurs physiologically. The cystamine reacts with the protein via available sulphydryl groups, and although three cysteamine residues are incorporated, two of these can be removed again, without loss of the newly gained activity. All cysteamine residues are rcmoved, and the enzyme deactivated, by cxposure to reduced glutathione, and the authors suggest a coupled feedback scheme, whereby this new method of regulation can function. It is supposed to operate independently of the established process of inhibition by AMP. 